\title{
A Research in China Based on the Moral Judgement Test
}

Shaogang Yang (Guangdong University of Foreign Studies)

Huihong $\mathrm{Wu}$ (Hohai University)

\section{An theoretical analysis of children's character development and the ability of moral judgment}

It is an excellent tradition that China's education emphasizes moral education and has paid special attention to the cultivation of students' morality for quite some time. At the beginning when a child has some dim consciousness, the adults would pass on to him some of good characters with the forms such as telling stories orally, and therefore, the idea that "a positive education should be given to an individual when he is young so as to make him have good habits of moral behavior" has been an important principle and method in China's moral education for a long time. Many outstanding persons in the long history of the Chinese nation have become the best examples to cultivate children to have moral characters. The story "Kong Rong declined to pears" (Gu, 2002, p. 911), for example, is a typical story that is known to every household in China. Kong Rong (153 208) is Confucius' grandson of the twentieth generation who was born in the Han Dynasty and a famous writer. Once upon a time when he was 4 years old, his parents asked him and his brothers to eat the pears which were different size, some were large and some small. Kong Rong just take the smallest pear and let his brothers to have the larger ones. What the story expresses is to foster a kind of virtue of modest decline.

With the development of politics, economy, culture and education and so on in the modern society, however, some contradict situations with the traditional ideas 
have appeared in China's moral education, that make people's values face serious challenges. People have to ask whether the contemporary could put into practice the virtues that they learned from childhood while they are encountering the temptation of the personal material interest. For instance, the modest decline mentioned in the above story has been regarded as a kind of virtues, but many people think that it implicates the reject to the competition and initiative, without which people are very difficult to live in this society full of severe competition. The new generations who are living in the period of the social transfer often feel morally perplexed and at a loss while they are facing the moral realities and the social conflicts stemming from the families, schools and the societies. They are wondering whether they should stick to the traditionally ethical ideas or break through the tradition and bring forth new ideas. Nowadays China's moral education still pays more attention to the instruction and instilling of the traditional virtues, even though the curriculum reform has made it changed a bit, but rarely induces the students to learn to make their own and correct judgment while they are having some moral conflicts and solving the real problems.

It is obvious that there exist some divergence of vies and some challenges from the real practice in the things such as how to promote the development of one's moral character. Even in the contemporary world the two approaches seem to argue in the ways in which people's moral character should be cultivated. On the one hand, some scholars advocate that only by virtue of the inculcation of the traditional virtues and through the instruction of the moral knowledge and the training of the moral habits, can children's character develop in the direction that is consistent with the society. For example, Thomas Lickona (1991), who is the representative of character education, pointed out with confidence:

\footnotetext{
Given the enormous moral problems facing the country, their deep social roots, and the ever-increasing responsibilities that schools already should, the prospect of taking on moral education can seem overwhelming. The good news, as we will see, is that values education can be done within the school day, is happening now in school systems all across the country, and is making a positive difference in the moral attitudes and behavior of students, with the result that it's easier for teachers to teach and students to learn. (p. 22)
}

And on the other hand, what the psychology of moral cognition pays more attention to is how to teach a child to make correct moral judgment and reasoning while facing the moral dilemmas and how to seek the reasonable solution of the conflicts. Thus, "If people hope to find out the moral foundation that could reasonably solve the moral conflicts between the two sides, they have to be not only able to understand the point of views that support their arguments, but also have the ability to understand the opinions that are inconsistent with their ideas. This ability is just 
the one of moral judgment, and it has been increasingly approved to be the centre of one's morality, and to be the basic moral element in the modern societies (Wu, 2005). The well-known psychologists Jean Piaget and Lawrence Kohlberg's cognitive theory of moral development belongs to this approach.

German psychologist Georg Lind shares the same idea with this approach. He has made over 20 years of research on it, and developed his own "Double aspect theory of moral behavior and development". Based on this theory he designed the well-known "Moral Judgment Test (MJT)" in 1976. During the process of the academic communication with George for many years, we deeply feel that this theory and its methods of research have plenty of enlightenment to Chinese moral education. Georg emphasizes the importance of the moral cognition (sometimes called moral abilities), and agrees with the definition of Kohlberg for the ability of moral judgment described in his early literature. He believes that the ability of moral judgment is "the ability an individual (based on his intrinsic moral principles) makes the decision and judgment for which one is moral, and the ability to put into practice based on the judgment." (Kohlberg 1964, p. 425)

Although the double aspect theory regards Piaget, Kohlberg and moral cognitive theory as its foundation, it is still quite different from the latter one. On one hand, Lind acknowledges that both moral cognition and affection are parallel, and therefore they are logically distinguishable and can be measured independently. On the other hand, he makes further definition and discrimination of the two aspects. In our opinion Lind is the first beside Piaget to dare to face squarely the relationship between the moral cognition and moral feelings, and tries to interpret and analyze the complicated relationship. In addition, Lind uses the same test to measure the two aspects of an individual's morality that makes the results more clear-cut and more approach to human life.

Morality is very complicated and therefore the research of morality should pay special attention to the ecological system, that is, it must have an intimate connection with a person's moral life and carefully take account of the situations in which moral behavior appears. Lind ingeniously combines the psychological test and the experimental design, and his MJT basically follows the interpretation of this concept. Up to now, most of the research related to MJT have been proceeded in the Western countries. We are not sure what is the present status of the ability of moral judgment in China's adolescents and youths, how an individual's consideration of morality play its role while he is making his moral judgment, which factors have influenced the development of an individual's capacity of moral cognition, the intelligence, gender and ages as we usually think, or our education? 
With such Doubts we communicated with Dr, Lind from whom we found that someone in Hebei Province, China did some research with MJT(Zhao, 2003) and has made it revised with the Chinese version. Supported by Dr. Lind, we happily got the English version of MJT, and used the Chinese adolescents and youths as the participants to make our own research in Jiangsu Province.

\section{Introduction of our empirical research}

\section{The sampling}

The time of our sampling is in the year 2003. Since the validity of MJT might be influenced by the sampling of the participants, we take the following six factors into account:

(1) Grades: 10: (Grade 1, 2, 3 in junior high school; Grade 1, 23 in senior high school; freshman, sophomore, junior and senior of undergraduates).

(2) Class features: 2: fast learning class and ordinary class/ undergraduates and junior college students.

(3) Gender: 2 male/ female.

(4) Districts: 4 cities: (Nanjing, Danyang, Wuxi and Suzhou in Jiangsu Province).

(5) Schools, colleges and universities: 6: (The Fourth High School of Nanjing, Industrial College of Nanjing Agricultural University, Nanjing Normal University, The Second High School of Wuxi, Danyang High School, and Suzhou University of Science and Technology).

(6) Total number of the participants: 724 ( 403 males and 321 females).

\section{The instrument}

MJT of the Chinese version. Some scholar in China has made a necessary verification for its cross-cultural validity. Some indicators that show its important validity such as the order of preferences, quasi-simplex structure and cognitive-affective parallelism meet the criterion of revision.

There are two dilemma stories which are followed with 12 questions for each story that require the participants to make their own judgment. We have added some questions behind the test that particularly ask the Chinese students to answer in order to understand their feelings to the test and their self-knowledge. 


\section{Results}

(1) The analysis of the students' attitude of the two dilemmas (See Table 1)

\begin{tabular}{c|c|c|c|c|c|c|c|c|c}
\hline \hline & -4 & -3 & -2 & -1 & 0 & 1 & 2 & 3 & 4 \\
\hline \hline Worker's Dilemma & 144 & 110 & 158 & 104 & 86 & 43 & 46 & 21 & 12 \\
\hline Doctor's Dilemma & 69 & 44 & 72 & 40 & 76 & 75 & 142 & 120 & 86 \\
\hline \hline
\end{tabular}

Table 1. The distribution of the participants' attitude to the two dilemmas

It could be seen from the distribution that mast students hold the more opposite attitudes to the stealing behavior of the workers in the first dilemma, and hold a little bit more agreeable attitude to the doctor's murdering behavior (euthanasia) in the second dilemma. In our further analysis we think there are several reasons for these:

First, although both the theft and murder commit the crime, the leading characters in the story commit the offense by no means accidental. Comparatively speaking, people regard the stealing behavior as worse than the euthanasia, and therefore should be punished more severely.

Second, although the purpose of the stealing behavior is to guard the personal dignity, the behavior itself looks like the one that answers blows with blows, which is not permitted by the traditional Chinese culture. On the contrary, it seems that the doctor has done a good thing in this story though he makes the patient die. Because he exerts the euthanasia based on his good wishes to eliminate the pains that the patient cannot bear, and he does so according to the patient's free will and without making any harm to any other people. Although there are no clear rules in China's law about the euthanasia, it has not so strict limitations on moral principles as it does in the Western countries. 
74 | Yang Shaogang, Wu Huihong

(2) Grade distribution of the students' C scores with MJT (See Table 2)

\begin{tabular}{|c|c|c|c|c|c|c|c|c|c|}
\hline $\begin{array}{l}\text { Grade } \\
1(\mathrm{~J} . \mathrm{H})\end{array}$ & $\begin{array}{c}\text { Grade } \\
2\end{array}$ & $\begin{array}{c}\text { Grade } \\
3\end{array}$ & $\begin{array}{l}\text { Grade } \\
1(\mathrm{~S} . \mathrm{H})\end{array}$ & $\begin{array}{c}\text { Grade } \\
2\end{array}$ & $\begin{array}{l}\text { Grade } \\
3\end{array}$ & Freshman & Sophomore & Junior & Senior \\
\hline 24.330 & 21.852 & 21.220 & 30.223 & 30.981 & 27.061 & 29.209 & 27.263 & 26.921 & 31.443 \\
\hline
\end{tabular}

Table 2. C scores of the students' MJT in various grades

According to the total distribution, it shows the regular tendency that the $\mathrm{C}$ scores increase with the students' ages and grades, and it is consistent with Dr. Lind's point of view that education is an important factor that influences one's ability of moral judgment. But it also shows some fluctuation of the $\mathrm{C}$ scores among different grades within the junior high and senior high schools and the universities. Taking account of the wide scope of sampling, we make the following further analysis.

\section{(3) Further analysis of the students' C scores with MJT}

Based on the data acquired from the test, we makes the further analysis of the participants' genders, different grade within a certain school (the similarity of the students' learning background), and the students with the same grade but different features (their academic scores, key schools and ordinary schools, and the colleges and universities). The conclusions are as follows:

First, the comparison of the $\mathrm{C}$ scores between the male and female students shows: $p=0.26$, and therefore there is no significant difference between the two genders in their $\mathrm{C}$ scores.

Second, it shows through the comparison of the $\mathrm{C}$ scores among various grades within a certain school that there is no significant differences except Nanjing Agricultural University $(p=0.006)$. According to our analysis, the reasons are might be:

a. In the high schools the age scope of the students is usually across 3 years, and in China's high schools the academic competition is very serious that makes the students put their stress mainly on learning. The students have little opportunity to consider the problems such their moral responsibilities for the society, and thus there appear no significant differences among various grades with the same school. 
b. The samplings in the different universities are also different. For example, in Suzhou University of Science and Technology we acquire the sample from a large class in which the students come from various professions, and thus no significant differences appear in this university. In Nanjing Agricultural University, however, we take the small class as our sample, so that the students have consistency and similarity in their profession, and therefore there is significant differences among various grades. Further analysis reveals that the $\mathrm{C}$ scores of the freshmen and seniors are significantly higher than those of the sophomores and juniors, and the seniors have the highest $\mathrm{C}$ scores. It finds out through our interview with the participants that the freshmen just entered the university (in September), and our sampling started from December. The students had just finished the military training (usually for one month) and had not entered the learning readiness completely, and many students began to commit to and enjoy the activities of various students communities. The sophomores and the juniors have usually entered into the learning status completely, and so they are willing to spend more time in their academic study but not in the other activities. The fact that the seniors are facing the internship and finding suitable jobs after graduation makes them to transfer their focus from on the pure learning to the social activities which require them to take on more responsibilities.

Thirdly, a comparison of the C scores between the two-year college students and the four-year university students reveals: Sig. $=0.279$, and a comparison between the students in the key schools and the ordinary schools shows: Sig. $=0.280$. That states that there are no significant differences between them. in their C scores of MJT.

\section{(4) Analysis of the students' other related variables}

First, an investigation to their feelings about doing MJT. The questions are shown in the following table:

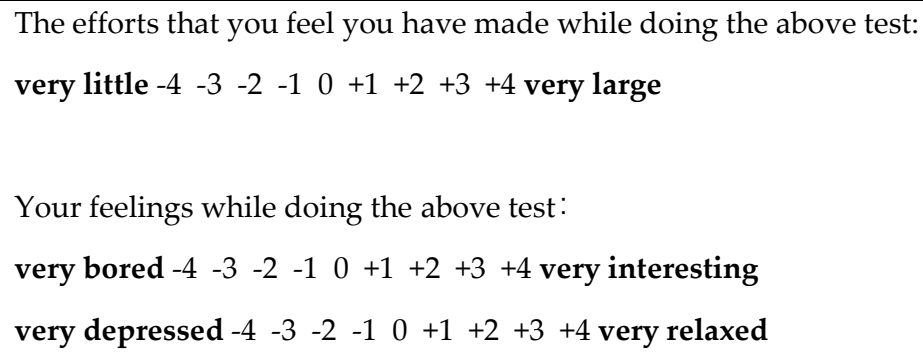

Table 3. Participants feelings of finishing the questionnaire 
It reveals through the investigation that:

a. the participants are generally interested in the manner of presenting the dilemmas that inform us that using dilemmas as the materials for school moral education is an effective and interesting form.

b. Since the dilemmas are related to some core values, and there exist some conflicts among some of them, the students usually made more efforts while doing MJT. It shows that the method of the presentation has really initiated them to consider the moral problems seriously.

c. As for the feelings while doing the above test, it is relatively well-distributed on the two dimensions of "very depressed" and "very relaxed". We found out through the interview that there are two reasons for the students to feel depressed: one is that they didn't adapt their thinking to the method of presenting the opposite ideas (usually high school students), the other reason is that they feel it really difficult to make their judgment in facing the conflicts with two opposite values (usually university students).

Second, a related investigation to the university students. The items are as follows:

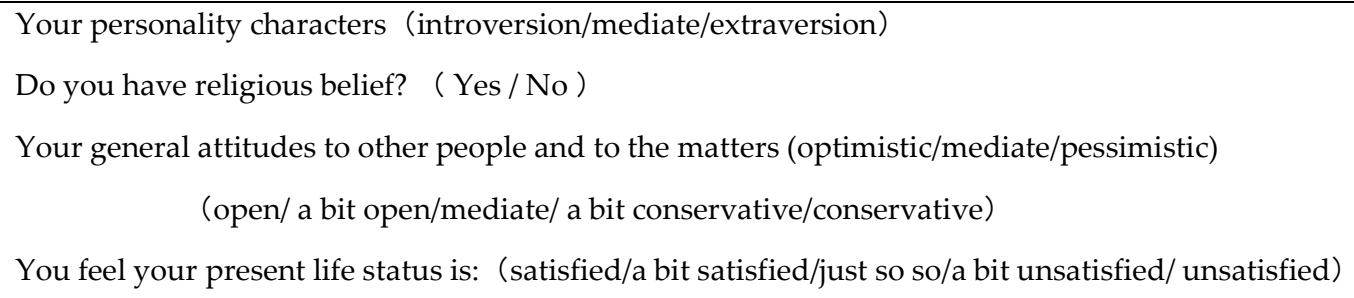

Table 4. Questions for university students

It reveals:
a. half of the participants have the mediate personality characters $(51.3 \%)$. The ratio of the introverted students is $28.2 \%$, and the extraverted is $18.7 \%$.
b. In the dimension of the religious belief $89.9 \%$ students have, and only $10.1 \%$ have not.
c. As for the attitudes of the students, $61.2 \%$ of them are optimistic, $33.2 \%$ are mediate, and $5.5 \%$ are pessimistic. $13.8 \%$ are open, $49.5 \%$ are a bit open, $21.0 \%$ are mediate, $14.4 \%$ are a bit conservative, $1.3 \%$ are conservative.


d. In the fourth item the percentage of the students who feel satisfied is $8.4 \%$, a bit satisfied is $36.2 \%$, just so is $33.4 \%$, a bit unsatisfied is $18.9 \%$, and unsatisfied is $3.1 \%$.

We could find that most of the students in the universities of the present Chinese society have the tendency of extraversion; they usually have religious belief; they are basically optimistic and have open-minded in their attitudes to the other people and matters; and they are generally more satisfied to their present life status ( It should be noted that the participants are in the Jiangsu Province and most of them are living in the rich cities of Jiangsu). Therefore, although the dilemmas might sometimes involve the negative information such as murder and theft, and might cause the students to have some psychological conflicts, we infer that they would usually not influence the extent to which they accept the behaviors and the ability for them to make their own moral judgment.

Thirdly, a related investigation to the students in the junior and senior high schools. The items are as follows:

Do you think that your thought could usually be understood by your classmates?

Yes ( ) Sometimes yes, but sometimes no ( ) No ( )

Do you think you could usually understand your classmate nearby?

Yes ( ) Sometimes yes, but sometimes no ( ) No ( )

Table 5. Questions for junior and senior high school students

It found out:

a. For the first question, $27.2 \%$ of them think that they could usually be understood by their classmates, $67.8 \%$ think they could sometimes be understood, but sometimes not, and $5 \%$ of them think that they could not be understood.

b. $44.9 \%$ of the participants think that they could understand their classmates, $54.3 \%$ think they could sometimes understand them, but sometimes not, and $0.8 \%$ of them think that they could not understand their classmates. 
It could be seen that in the two dimensions the middle school students in China tended to think that they could usually understand each other. It tells us that, on the one hand, they have possessed the abilities to make the cognitive and affectionate judgment and has shown more volitions of doing so. It also shows that, on the other hand, they are usually lack of the communications with others on some problems, and therefore many of them think they could not be understood by others. According to our opinions, the school education should provide the students with, besides the knowledge and skills, a certain opportunity of communication, so that they could have the discussions about some questions in which they are interested, especially some questions concerning the values. In this way they could not only understand the point of views of their contemporaries and get the consensus, but also acquire the guidance of their teachers and parents.

\section{Conclusions}

Through our empirical research, we have got some conclusions of the moral development of the adolescents and youths in contemporary China.

(1) In the emotional aspect of the moral attitude, most of the participants have a relatively suitable attitude towards the dilemmas, without going to extremes and taking a mean course so much as we expected before.

(2) Although the C scores in the MJT in China (the mean scores in the middle schools are 26.9, in the higher universities 28.86) are comparatively lower than those in the Western countries), they meet the developmental regularity, that is, there are significant differences for their $\mathrm{C}$ scores among various grades. The general tendency is that the students have higher $\mathrm{C}$ scores with the increase of their grades, and therefore it might be said that education has played a very important role for the development of the students' morality, meanwhile positive commitment to the activities of the society and the school communities is beneficial to the increase of their moral abilities.

(3) There is no significant difference in their $C$ scores between the male and female, between the key school and the ordinary school and between the colleges and the universities, and thus it might be inferred that such factors as intelligence and gender will not directly influence the moral development.

(4) The students in the junior and senior high schools usually have rare opportunity to communicate broadly with others, and therefore they think to a large extent that they are not understood by others even though they have possessed the abilities of making judgment of their cognition and emotion, and they have shown the aspirations with every effort. 
(5) At present the Chinese students usually hold an optimistic and openminded attitudes towards the other people and affairs, and are provided with the capacity of making objective and calm analysis for the problems with values.

\section{References}

Gu., M. (Ed.) (2002). Dictionary of Education. Shanghai: Shanghai Education Press.

Kohlberg, L. (1964). Development of Moral Character and Moral Ideology. In: M. L. Hoffman \& L. W. Hoffman (Eds.), Review of child development research, Vol. I. New York: Russel Sage Foundation, pp. 381-431.

Lickona, T. (1991). Educating for character: How our schools can teach respect and responsibility. New York: Bantam Books.

Lind, G. (1982). Experimental Questionnaires: A New Approach to Personality Research. In A Kossakowski \& K. Obuchowski (Eds.), Progress in psychology of personality (pp. 132-144). Amsterdam, NL: Northholland.

Lind, G. (1999). Scoring of the Moral Judgment Test (MJT). Konstanz: University of Konstanz.

Piaget, J. (1965). The moral judgment of the child. New York: The Free Press.

$\mathrm{Wu}, \mathrm{H}$. (2005). A new visual angle of moral research: The theoretical and empirical research of the Moral Judgment Test. An unpublished master thesis in Nanjing Normal University.

Yang, S. \& Wu, H. (2008). The Features of Moral Judgment Test among Chinese Adolescents. Asia Pacific Education Review. Vol. 9 (3).

Zhao, Z. (2003). A correlatiive research on volunteer service activities and moral development of the senior high school students. An unpublished master thesis in Hebei Normal University. 
80 I Yang Shaogang, Wu Huihong

\author{
Yang Shaogang (Guangdong University of Foreign Studies) \\ Wu Huihong (Hohai University)
}

\title{
A Research in China Based on the Moral Judgement Test
}

\begin{abstract}
In this research we use "the Moral Judgment Test" as an instrument that is developed by Professor Georg Lind in 1976, but is a Chinese version with some revisions, with 724 students whose ages are from 14 years old to 27 years old as the participants. The results show that: the C-scores are increased with the increase of the students' age, but there are some fluctuations among different grades. It is obvious that the school education do could improve students' abilities of moral judgment, but there exist some instability factors. There are no significant differences in their C-scores between male and female students, among different grades within certain schools and universities, and among students with various professions, the key schools and the regular schools as well as the two-year and the four-year college students.
\end{abstract}

Keywords. Moral Judgment Test, C scores, China, Adolescents

Authors. Yang Shaogang is a professor of Psychology in Department of Applied Psychology, Guangdong University of Foreign Studies. Wu Huihong is a lecturer in Hohai University.

Contact Address. Baiyun Dadao Bei, Guangzhou City, 510420, Guangdong Province, P. R. China.

Citations. Reference this paper as: Yang, S., Wu, H. (2011). A Research in China Based on the Moral Judgement Test. Ethics in Progress Quarterly, Volume 2, Issue 2, pp. 69-80, available online at ethicsinprogress.org. 